\title{
La lesión enorme en Argentina y Colombia: un estudio comparado*
}

1 Rubén S. Stiglitz

1 Mariana Bernal Fandiño

Resumen: La lesión enorme busca sancionar el desequilibrio contractual que se presente durante la etapa de formación del contrato. La regulación de esta figura debe ponderar la necesidad de la seguridad jurídica en las transacciones con la importancia de la equidad y la justicia contractual. Los ordenamientos jurídicos han optado por distintas posiciones frente a ese reto, por lo que la comparación de dos sistemas jurídicos como el colombiano y el argentino resulta ilustrativa para analizar la eficacia de la lesión para sancionar desequilibrios significativos en los negocios jurídicos contemporáneos.

Palabras clave: Justicia contractual, equilibrio contractual, lesión enorme.

Fecha de recepción: I 5 de marzo de 20I 7. Fecha de aceptación: 2 de octubre de 2017 . Para citar el artículo: Stiglitz, R. S. y Bernal Fandiño, M., "La lesión enorme en Argentina y Colombia: un estudio comparado", Revista de Derecho Privado, Universidad Externado de Colombia, n. ${ }^{\circ} 33$, julio-diciembre de 20I7, I37-I59. DOI: https://doi.org/Io.I860I/oI 234366.n33.06

** Abogado, Facultad de Ciencias Jurídicas y Sociales, Universidad Nacional de La Plata, Argentina. Doctor en Derecho y Ciencias Sociales, Universidad Nacional de Buenos Aires, Argentina. Profesor, Facultad de Derecho y Ciencias Sociales, Universidad Nacional de Buenos Aires, Buenos Aires, Argentina. Contacto: rstiglitz@estudiostiglitz.com.ar

*** Abogada, Pontificia Universidad Javeriana. Máster en Derecho Comercial y máster en Derecho Internacional Privado, Universidad de París II. Doctora en Ciencias Jurídicas, Universidad Javeriana. Profesora investigadora, Universidad Sergio Arboleda, Bogotá, Colombia. Contacto: mariana.bernal@usa.edu.co 


\title{
The Lesion in Argentinian and Colombian Law: A Comparative Approach
}

\begin{abstract}
Aвstract: The lesion intends to sanction the contractual imbalance that occurs during the stage of contract formation. The regulation of this figure should weigh the need for legal certainty in transactions with the importance of equity and contractual justice. Legal systems have chosen different positions face to this challenge, so the comparison of two legal systems such as the Colombian and the Argentine is illustrative to analyze the effectiveness of the lesion in contemporary legal business.
\end{abstract}

Keywords: Contractual justice, contractual balance, lesión.

\section{Introducción}

La importancia del equilibrio en los contratos se ve reflejada en distintas figuras según la etapa contractual. En el momento del perfeccionamiento del negocio encontramos la ausencia de lesión enorme o de vicios del consentimiento que afecten la libertad y equidad del acuerdo como requisitos para la validez del contrato. En la fase de ejecución, existe la posibilidad de terminar o revisar el contrato frente a circunstancias imprevisibles y sobrevinientes a su celebración (que alteren gravemente la ecuación económico-financiera que el contrato entraña).

La lesión enorme, entonces, es uno de los mecanismos que pretenden sancionar los negocios jurídicos desequilibrados. Las legislaciones al regular esta figura se enfrentan al reto de ponderar el principio de la seguridad jurídica y el respeto por la autonomía privada, por un lado, y la equidad y la justicia, por el otro.

La comparación entre los ordenamientos jurídicos de Argentina y Colombia nos ilustra dos posiciones diferentes para responder a esta problemática, por lo que iniciaremos este estudio revisando el concepto de lesión, sus antecedentes y fundamento jurídico, los elementos que la constituyen, su ámbito de aplicación y sus efectos en ambos países.

\section{Concepto de lesión}

El concepto de lesión se utiliza en la teoría clásica del negocio jurídico para referirse a un quebranto o daño que en el momento de su perfeccionamiento altera su equilibrio y usualmente se acompaña de un calificativo que se refiere a su gravedad (lesión grave, lesión enorme). Se ha definido como el perjuicio que sufre una de las partes de un contrato por una desigualdad de valor entre las prestaciones ${ }^{\mathrm{I}}$.

I Flour, A., Les Obligations, t. I : L'acte juridique, Francia, Sirei, I77. 
Esta visión es exclusivamente objetiva, pues solo atiende al desequilibrio significativo de las prestaciones.

En otras legislaciones no basta con el elemento objetivo, pues se exige una actuación de explotación o aprovechamiento, un elemento subjetivo que se sume al desequilibrio. En este sentido, se ha señalado que la lesión es el daño que sufre un contratante en el momento del perfeccionamiento del acuerdo al asumir en forma injustificada prestaciones significativamente desproporcionadas como resultado de una conducta contraria al principio general de la buena $\mathrm{fe}^{2}$.

\section{Antecedentes y fundamento jurídico}

Las nociones de equilibrio y justicia conmutativa son fundamentales en la importancia que tiene la lesión como causal de invalidez de los negocios jurídicos.

El fundamento de la lesión se encuentra en el principio de preservación del sinalagma, que no es otro que el que presupone un intercambio recíproco de obligaciones en relación de equivalencia.

Existen antecedentes de la figura de la lesión desde el derecho romano, con el recurso in integrum restitutio, que buscaba proteger a los que sin tener una madurez suficiente resultaban perjudicados por un acuerdo desequilibrado. Además, surgió la acción rescisoria por lesión enorme a favor del vendedor de bien inmueble perjudicado en más de la mitad de su valor ${ }^{3}$.

En la Edad Media se acercó la noción de lesión a la de dolo, pues se consideraba que para configurarse la lesión requería de engaño o artificio. Los canonistas lucharon a favor del precio justo, pero los comerciantes no aceptaban la lesión como una regla general4.

El Código de Napoleón, después de fuertes debates entre la seguridad jurídica y la necesidad de equivalencia de las prestaciones en los contratos onerosos, consagró la figura de la lesión, pero de forma muy restrictiva (art. i i i 8). Sin embargo, en Francia la lesión se ha ampliado por vía jurisprudencial (posibilidad de solicitar al juez la disminución de honorarios que se consideraran excesivos de mandatarios y otros agentes de negocios) o normativa (Ley i I de marzo de 1957 para el contrato de concesión de derechos de explotación económica de obra literaria o artística; Ley 28 de diciembre de i966 que contempló la lesión en los intereses de préstamo de consumo, entre otros).

Pothier explicaba que la equidad debe observarse en las convenciones y, dado que esta en el comercio se basa en la igualdad, el contrato se vicia si uno de los contratantes da más de lo que recibe, aunque el otro contratante no haya

2 Ordoqui, G., Desequilibrio en los contratos, Montevideo, Universidad Católica, 2007, 395.

3 Chantepie, G., La lésion, LGdJ, 8.

4 Hinestrosa, F., Tratado de las Obligaciones iI, vol. i, Bogotá, Universidad Externado de Colombia, 2015 , I I 33 . 
acudido a ningún artificio para engañarlo; basta la inequidad de las prestaciones para configurar la lesión 5 .

Se evidencia entonces que, desde Roma hasta el Code Civile francés y las codificaciones inspiradas en este, se tuvo en cuenta un elemento objetivo para determinar la lesión.

Posteriormente, en el derecho alemán, el вяв recoge la lesión, pero bajo un nuevo ropaje, pues se introduce en el parágrafo ${ }_{3} 8$ la sanción a los negocios contrarios a la moral y las buenas costumbres, añadiendo elementos subjetivos a la desproporción objetiva. En efecto, se niega la validez de un negocio en el que una persona, aprovechándose de la necesidad, falta de experiencia o debilidad de otra, genera una ventaja desproporcionada para sí o para un tercero.

Es así como durante el siglo xx se evidencia la influencia del вGв, pues se incorpora la lesión en las nuevas legislaciones, pero ya no solamente teniendo en cuenta el elemento objetivo del derecho romano, sino además elementos subjetivos como el aprovechamiento del estado de inferioridad del lesionado.

Aunque en el derecho anglosajón prevalece la intangibilidad del contrato, la llamada doctrina de unconscionability, consagrada en la Sección 2-302 del Uniform Commercial Code, le permite al juez invalidar la totalidad de un contrato o algunas cláusulas si eran fundamentalmente injustas en el momento de su celebración.

\section{Naturaleza jurídica}

Analizar la naturaleza jurídica de la lesión es importante para delimitar la figura, entender sus alcances y utilidad.

En Colombia, el Código Civil establece la lesión como una anomalía puramente objetiva del negocio y por esto recibe un tratamiento autónomo ${ }^{6}$, no se considera un vicio del consentimiento ni se sanciona con nulidad 7 . En cambio, en el derecho argentino se considera que la lesión completa las causas de nulidad de los actos jurídicos, aunque "[l]a doctrina discrepa acerca de si la lesión constituye un vicio de la voluntad -por falta de libertad-o bien un vicio en el objeto o en la causa del negocio jurídico" .

Stiglitz considera que la nulidad del negocio se produce porque la lesión es un vicio de la voluntad o del consentimiento al formarse el contrato diferente

5 Pothier, R. J., Traite des obligations I, C I, 39 I y ss.

6 Hinestrosa, F., Tratado de las Obligaciones il, vol. i, Bogotá, Universidad Externado de Colombia, 20I5, II 37 .

7 Corte Suprema de Justicia, Sala Civil, M. P.: Ricardo Uribe Holguín, Colombia, I 4 de octubre de 1976.

8 Mosset Iturraspe, J., Contratos, Buenos Aires, Rubinzal-Culzoni, I995, p. I76. 
del error, el dolo o la violencia ${ }^{9}$. Según esta postura, la existencia del mencionado vicio del consentimiento se sanciona con la acción de nulidad y modificación que establece el artículo 332 del nuevo Código Civil y Comercial argentino que encuentra su fundamento, dado que si el negocio jurídico requiere discernimiento, intención y libertad, los presupuestos de hecho de la lesión determinan la ausencia de libertad de elección. Esta falta de libertad afecta a la voluntad a tal punto que el negocio es inválido ${ }^{\mathrm{IO}}$, pues la voluntad del lesionado se encuentra viciada por condicionamientos ligados a su situación de necesidad, ligereza o inexperiencia, que lo llevan a optar por una decisión que en otras circunstancias no hubiera adoptado ${ }^{\text {II }}$. Al presentarse la lesión, el negocio carece de eficacia originaria $^{\mathrm{I} 2}$, es inválido desde su formación ${ }^{\mathrm{I} 3}$.

Ahora bien, si se analiza la cuestión desde la perspectiva del lesionante, el beneficiado por el acuerdo obra con el propósito deliberado ${ }^{\mathrm{I} 4}$ de aprovechar la posición de inferioridad de la otra parte. Ese elemento subjetivo que exige la lesión en el derecho argentino evidencia que uno de los contratantes actúa "con la finalidad específica del aprovechamiento o explotación de la necesidad, inexperiencia o ligereza de la otra" ${ }^{5}$. Esta exigencia lleva al análisis de la noción de causa, y los límites a que está sometida la prueba de los móviles.

Así las cosas, el motivo determinante para contratar de quien se aprovecha de la debilidad del otro no se halla incorporado al campo contractual, sino que se mantiene oculto. En consecuencia, no es factible suponer que el lesionado se halla vinculado con lo que ignora. Entonces, el aprovechamiento por una parte de la necesidad, ligereza o necesidad del otro no puede constituirse en la causa final del acto, sino en el móvil (inmoral) individual que impulsa a contratar al primero.

9 Stiglitz, R. S., Contratos civiles y comerciales, Parte General, t. I, n. ${ }^{\circ} 276$, Buenos Aires, AbeledoPerrot., I998, 299; Cifuentes, S., Negocio jurídico, Buenos Aires, Astrea, i986; Mosset Iturraspe, J., Contratos, t. II-в, Santa Fe, Rubinzal-Culzoni, I995, I 78; y Llambías, J. J., Código civil anotado, Buenos Aires, Abeledo-Perrot, I07.

io Díez-Picazo, L., Fundamentos del derecho civil patrimonial. Teoría del contrato, n. $^{\circ}$ 5, Madrid, Civitas, I996, 457 .

I I Llanos de Ferreira vs. Abdenur A., ${ }^{2}{ }^{\text {a }}$ CC Santiago del Estero, LL NOA, I 998-I420, I4 de abril de I998.

I 2 Barbero, D., Sistema de derecho privado, t. I, n. ${ }^{2} 27,529$.

I 3 Messineo, F., Manual de Derecho Civil y Comercial (trad. Melendo, S. S.), t. II, n. ${ }^{\circ}$ ıo, Buenos Aires, Ejea, I97 I, 44I.

I4 Yordano vs. Flores J., CCiv, Com. y Contencioso Administrativo, San Francisco, Llc, I 996-ı o98,

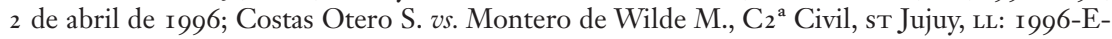
439, 5 de junio de I995; Furque J. vs. Mateo D., Com. Minas, Paz y Tributario, Mendoza, LL Gran Cuyo, I999-62 I, 2 I de diciembre de r998, donde se alude a "una voluntad dirigida" del aprovechador.

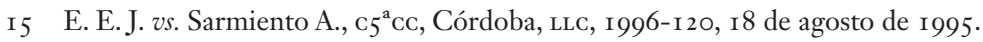




\section{Elementos}

La lesión ha sido sancionada de diversas formas a través del tiempo y en los distintos ordenamientos jurídicos.

El derecho colombiano, inspirado fundamentalmente en el Código de $\mathrm{Na}$ poleón, consagra la lesión para ciertos casos particulares y teniendo en cuenta únicamente un elemento objetivo de desproporción en las prestaciones.

En el derecho argentino, en cambio, la lesión se halla prevista de manera general en el artículo $33^{2}$ del Código Civil y Comercial incorporando no solamente el elemento objetivo, sino también el subjetivo, así:

Puede demandarse la nulidad o la modificación de los actos jurídicos cuando una de las partes, explotando la necesidad, debilidad jurídica o inexperiencia de la otra, obtuviera por medio de ellos una ventaja patrimonial evidentemente desproporcionada y sin justificación. Se presume, salvo prueba en contrario, que existe tal explotación en caso de notable desproporción de las prestaciones. Los cálculos deberán hacerse según valores al tiempo del acto ${ }^{16} \mathrm{y}$ la desproporción debe subsistir en el momento de la demanda. El afectado tiene opción para demandar la nulidad o un reajuste equitativo del convenio, pero la primera de estas acciones se debe transformar en acción de reajuste si éste es ofrecido por el demandado al contestar la demanda. Sólo el lesionado o sus herederos pueden ejercer la acción.

Analizaremos entonces, a continuación, los dos elementos que se han tenido en cuenta para establecer la existencia de la lesión en los negocios jurídicos.

\section{A. Elemento objetivo}

El elemento objetivo de la lesión requiere de la obtención, por una de las partes, de una ventaja evidentemente desproporcionada. Ese desequilibrio significativo debe resultar de una confrontación de las prestaciones ${ }^{17}$.

Esta desproporción puede ser fijada por la ley en términos generales o estableciendo para cada caso en particular una medida mínima del desequilibrio. El derecho argentino y el colombiano ilustran estas dos visiones.

I6 Ortega R. vs. Bco. Bisel S, CCiv. y Com., Rosario, LL Litoral, 2008-580, 25 de febrero de 2008, donde se dispuso que "la desproporción tiene que existir en el momento del otorgamiento del acto".

I 7 Bianca, M., Diritto Civile. Il contratto, t. 3, Milano, Giuffrè, I987, 647. 


\section{El elemento objetivo de la lesión en el derecho argentino}

En el derecho argentino se configura el elemento objetivo de la lesión, salvo prueba en contrario, en caso de presentarse una notable desproporción de las prestaciones, a cuyo efecto los cálculos deberán hacerse según valores al tiempo del acto $^{18}$, debiendo aquella subsistir en el momento de la demanda ${ }^{19} \mathrm{y}$ apreciarse en concreto, es decir, en la realidad de los hechos investigados ${ }^{20}$.

La jurisprudencia argentina ha explicado que la lesión es un remedio excepcional en los contratos y que no implica que el juez se transforme en un renegociador de las relaciones obligacionales cuando son pactadas libremente por las partes, en la medida en que los contrayentes no se encuentren afectados por circunstancias extraordinarias ${ }^{21}$. Más específicamente se ha considerado que la lesión no debe configurar un medio para sustraer a los contratantes de las consecuencias negativas de un mal negocio ${ }^{22}$.

La jurisprudencia y la doctrina argentinas han precisado los términos de la ley en cuanto al elemento objetivo considerando que, al calificarse la desproporción como evidente, ha querido significarse que debe ser a tal punto manifiesta, grosera ${ }^{23}$, que nadie pueda dudar de $\operatorname{ella}^{24}$. Se ha entendido que la desproporción debe saltar a la vista para que se trate de un desequilibrio manifiesto ${ }^{25} \mathrm{y}$ perceptible ${ }^{26}$ o como una notable diferencia de valores entre las prestaciones de los contratantes ${ }^{27}$. Consideramos preferible utilizar la noción de "desequilibrio

I8 Ortega R. vs. Bco. Bisel S, CCiv. y Com., Rosario, Ll Litoral, 2008-580, 25 de febrero de 2008, donde se dispuso que "la desproporción tiene que existir en el momento del otorgamiento del acto"; Kuhn, O. vs. Banco de Entre Ríos, Cf. CApel. Civ. y Com. Concordia, Sala III, DJ, I996-2-920, I 5 de febrero de r996; Murad, A. vs. Llloyd Bank, CNCom., Sala A, I 4 de noviembre de I996, La Ley, I998-B, 699; DJ, I998-3-142.

i9 Alterini, A. A., Contratos, civiles, comerciales, de consumo, Buenos Aires, Abeledo-Perrot, I998, 38 I; D’Ambrogio, L. vs. Cottini, C., DJBA, sc Buenos Aires, I48-2352, 7 de marzo de i995; C. C.A. vs. C. S. M., CNCiv., Sala E, 29 de abril de I998; La Ley, I999-A, 406; DJ, I999-2-39.

20 Kuhn, O. vs. Banco de Entre Ríos, CaPel, Concordia, Sala III, DJ, I 996-2-920, I 5 de febrero de I996.

2 I Vázquez, E. vs. Huarte Empresa Arg. de Cemento, CNCiv., Sala L, 29 de noviembre de i996, La Ley, I997-D, 84; Von Petery, J. vs. Critto, A., CNCiv., Sala L, I 9 de febrero de r999, La Ley, 2000-C, 9 I I (42.699-S).

22 Lencina, A. vs. La Principal S. A., CNCom., Sala B, 24 de junio de 2003, La Ley, 2003-F, 643.

23 Gómez, C. vs. Álvarez, G., CNCiv., Sala H, 22 de octubre de i996, La Ley, I998-B, I 2.

24 Pedace, D. vs. Rodríguez, J., CNCiv., Sala A, 27 de octubre de r 994, JA, I995-IV-69.

25 Moisset de Espanés, L., La lesión y el nuevo artículo 954, Córdoba, Zavalía, I976, 82; Furque, J.

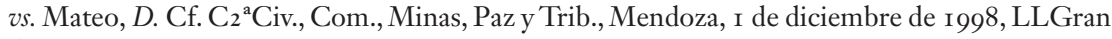
Cuyo, I999-62 I.

26 Almagro Construcciones vs. Agosto, E., CNCiv., Sala A, 4 de diciembre de I 992, La Ley, I 994B, 577; Davidoff, C. vs. Lynch, R., CCiv. y Com., Lomas de Zamora, Sala II, I de abril de I997, LLBA, I997-IO28.

27 Pedace, D. vs. Rodríguez, J., CNCiv., Sala A, 27 de octubre de I994, JA, I995-IV-68. 
significativo" en lugar de la referencia que hace el texto argentino sobre la ventaja "evidentemente desproporcionada", pues como lo ha afirmado la doctrina: "en la mayoría de las relaciones contractuales, las ventajas y sacrificios correspectivos no se encuentran en relación de proporcionalidad sino en relación de equivalencia" ${ }^{28}$.

Ilustra lo expuesto el pronunciamiento judicial en el que se dispuso que

corresponde hacer lugar a la revisión del contrato de mutuo con garantía hipotecaria, si se ha verificado una ventaja patrimonial evidentemente desproporcionada y sin justificación, en los términos del artículo 954 del Código Civil, a favor de la entidad bancaria que dispuso modificar arbitrariamente el plazo de amortización del préstamo, lo cual hace presumir la explotación de la parte económicamente más fuerte por sobre la más débil constituida, en el caso, por quien suscribió un contrato de adhesión ${ }^{29}$.

\section{El elemento objetivo de la lesión en el derecho colombiano}

En el derecho colombiano, el elemento objetivo se determina de forma diferente. La ley colombiana optó por sancionar una desproporción tarifada, es decir, la ley fija en ciertos casos la medida exacta en que se considera que existe desequilibrio.

Se establece de esta manera un nivel mínimo de desproporción por encima del cual se configura la lesión, pero solamente en los casos en que la ley ha considerado que ameritan una protección especial por su especial relevancia.

Se tiene en Colombia entonces una visión objetiva de la lesión, puesto que se presenta con el solo desequilibrio del negocio jurídico en la magnitud que la ley establezca. No se tienen en cuenta otros elementos, como la dependencia, la ignorancia de la víctima, el aprovechamiento del estado de debilidad o necesidad de la otra parte. Así lo ha indicado la jurisprudencia al interpretar la ley ${ }^{30}$ : "La lesión está estructurada en Colombia sobre un factor puramente objetivo (el justo precio), con toda independencia del móvil subjetivo y de la manera como éste haya influido en el consentimiento".

28 Товías, J. W., Algunas precisiones acerca del elemento objetivo de la lesión objetiva subjetiva, La Ley, I $996,43^{8}$.

29 Macia, L. vs. Banco Hipotecario, CCiv., Com. y Minería, Viedma, 25 de agosto de 2008, LL Patagonia, 2008-603.

30 Corte Suprema de Justicia, Sala Civil, M. P.: Ricardo Uribe Holguín, Colombia, I4 de octubre de 1976. 


\section{B. Elemento subjetivo}

El elemento subjetivo de la lesión exige que se presente una situación de vulnerabilidad de uno de los contratantes. El derecho colombiano ha incorporado la lesión basándose exclusivamente en el elemento objetivo, mientras que el derecho argentino tiene una concepción objetiva-subjetiva, pues se requieren los dos elementos.

Existen elementos subjetivos que atañen al lesionado y elementos subjetivos que atañen al lesionante.

\section{Elementos subjetivos que atañen al lesionado}

En el derecho argentino, el elemento subjetivo se manifiesta en la vulnerabilidad de uno de los contratantes que debe estar sustentada en su estado de "necesidad, debilidad psíquica o inexperiencia" (art. $332 \mathrm{CCCN}$ ). Este enunciado es limitativo, pues la pretensión de nulidad o modificación puede realizarse solamente sobre la base de los mencionados elementos subjetivos y que atañen a la víctima, por lo que no es factible invocar otros por vía de analogía ${ }^{3 \mathrm{I}}$ y la situación debe ser de tal relevancia que favorezca el aprovechamiento de la otra parte ${ }^{32}$. Revisaremos cada uno de estos elementos.

En primer lugar, se ha entendido que la necesidad implica la falta o escasez de lo que se requiere para la conservación de la vida, la salud, el honor, la libertad. Un estado de necesidad no se analiza únicamente desde un punto de vista material sino también moral, teniendo en cuenta la situación de agobio en que se puede encontrar una persona o su familia, como el caso del padre que urgentemente debe salvar al hijo próximo al fallecimiento ${ }^{33}$. No se llega al extremo de la indigencia, pues basta con que la necesidad sea de una notable importancia para el lesionado 34.

Se trata de una situación que disminuye la libertad de elección y que induce al sujeto a concluir el contrato 35 . Teniendo en cuenta lo anterior, es importante diferenciar el estado de necesidad de la fuerza como vicio del consentimiento.

3 I Llambías, J. J., cit., Código civil anotado, t. iI-B, IO7; Moisset de Espanés, L., op. cit., 89; Almagro Construcciones vs. Agosto, E, CNCiv., Sala A, 4 de diciembre de I992, La Ley, I994-B, 577; Pedace, D. vs. Rodríguez, J., CNCiv., Sala A, 27 de octubre de I994, JA, I995-IV-69.

32 Kuhn, O. vs. Banco de Entre Ríos, Capel, Concordia, Sala III, I 5 de febrero de i996, DJ, I9962-920.

33 SAcco, R., Il contratto, Torino, Utet, I975, 362; Davidoff, C. vs. Lynch, R., Cf. CCiv. y Com., Lomas de Zamora, Sala II, I de abril de I997, LLBA, I997-IO28.

34 Mirabelli, G., Dei contratti in generale, Torino, Utet, I 987,585 ; quien afirma que no es necesario que la necesidad sea extrema, ya que es suficiente que presente una notable importancia para el lesionado.

35 Messineo, F., Doctrina General del Contrato, cit., t. II, 9, 292. 
En la fuerza, la violencia la ejerce alguien, existe la intervención de una persona que ejerce coacción sobre otra para forzar la celebración de un negocio. En cambio, en el estado de necesidad existe una intimidación que no está determinada por una amenaza singular ${ }^{36}$.

El Código Civil colombiano ignoró, al regular la fuerza, la coacción proveniente de los acontecimientos ${ }^{37}$; por esta razón, juristas colombianos han asimilado o integrado el estado de necesidad a la fuerza, rechazando la afirmación de que esta deba ser producto de una persona ${ }^{3}$.

En segundo lugar, la debilidad psíquica se evidencia en el hecho o el dicho irreflexivo o poco meditado de quien no mide las consecuencias de las obligaciones que contrae. Se refiere a una situación de debilidad mental ${ }^{39}$ propia del pródigo, del débil mental y de otros estadios intermedios o fronterizos ${ }^{40}$, siempre enfermizos, que sitúan a la víctima en estado de inferioridad y, por tanto, la tornan vulnerable ${ }^{4 \mathrm{I}} \mathrm{e}$ indefensa ${ }^{42}$.

En tercer lugar, la inexperiencia hace alusión a quien carece de conocimientos o información, al profano con respecto al profesional43. En ciertos casos se hace referencia a la carencia de conocimientos técnicos o de costumbres comerciales de un lugar determinado44. Un fallo judicial argentino puede ilustrar el tema, pues se decidió que "habiendo quedado acreditada la avanzada edad y limitada instrucción de quien, por consejo de un operador de bolsa de su confianza,

36 Hinestrosa, F., Tratado de las Obligaciones II, vol. I, Bogotá, Universidad Externado de Colombia, 2015, 1093 .

37 El artículo I5 I3 del Código Civil colombiano establece que la fuerza como vicio del consentimiento se refiere a "todo acto que infunde a una persona un justo temor de verse expuesta ella, su consorte o alguno de sus ascendientes o descendientes a un mal irreparable y grave".

38 Pérez Vives, A., Teoría General de las obligaciones, v. I, 200.

39 Davidoff, C. vs. Lynch, R., CCiv. y Com., Lomas de Zamora, Sala II, I 7 de abril de I997, LLba, 1997-1028.

40 Llambías, J. J., Código civil anotado, cit., t. II-B, Io9, quien afirma que la ligereza, técnicamente, alude a un estado psíquico y patológico en el que se encuentra el sujeto que no mide el alcance de las obligaciones que contrae, no porque no quiera verlo, sino porque no puede hacerlo en razón de su situación de inferioridad mental; E. E. J. vs. Sarmiento, A., Cf. C $5^{\mathrm{a}} \mathrm{Civ}$. y Com. Córdoba, I8 de noviembre de 1995, LLC, I 996- I 20; Arce, S. vs. Parque Automotor, CCiv., Com. y Minería, San Juan, Sala I, I9 de mayo de 2005, LL Gran Cuyo, 2006- г20; Caino, J. vs. Baraban S.A., CCiv. y Com., Mercedes, Sala I, 28 de marzo de 2006, ED, 220-588.

4I Es el caso de quien suscribe un recibo cancelatorio "cuando se encontraba padeciendo una seria enfermedad -en la hipótesis, un día antes de una operación destinada a extirparle un tumor-"; Rivarola F. vs. Castillo Sacifia, Documentos y Locaciones, Tucumán, 5 de septiembre de 2004, LLNOA, 2005-5OI.

42 Mosset Iturraspe, J., Contratos, cit., i 82, quien señala que el hombre de hoy, sea por la fatiga, el estrés, la vida acelerada, los requerimientos del consumismo, la droga u otras razones, sufre limitaciones que en muchos casos lo llevan casi sin darse cuenta a contratar en desproporción.

43 Mosset Iturraspe, J., Contratos, cit., I82.

44 Moisset de Espanes, L., op. cit., 9i; Llanos de Ferreira, V. vs. Abdenur, A., Cf. C2 ${ }^{a}$ Civ. y Com. Santiago del Estero, I4 de abril de I998, LLNOA, I998-I42O. 
transfirió en forma gratuita la tenencia de acciones de su propiedad, resulta procedente encuadrar dicha situación en la noción de ligereza prevista en el artículo 954 del Código Civil como presupuesto subjetivo de la lesión"45. En otro caso, se encontró constituida la lesión en un contrato de locación en el que el locatario abusó de su posición de superioridad al imponer las cláusulas, reservándose unilateralmente el derecho de renovar el plazo de vigencia del contrato. En la especie, se fijó un plazo de tres años con un canon de alquiler que implicaba una ventaja irracional cercana al despojo ${ }^{46}$.

Dado que la necesidad, la debilidad psíquica o la inexperiencia inciden sobre la libertad de determinación del contrayente, algunas doctrinas argentinas, como se mencionó, ha considerado que se configura un vicio de la voluntad 47. Sin embargo, la jurisprudencia argentina ha precisado que no puede reclamarse la nulidad por lesión de un negocio celebrado entre un especialista y un lego únicamente por la diferencia de conocimiento que exista entre ellos ${ }^{4}$. En el mismo sentido, no procede la nulidad cuando quien alega debilidad es un comerciante a quien se le exigen ciertas capacidades mínimas para la administración de sus negocios49. Tampoco puede alegar la lesión quien en el momento de perfeccionar el contrato estaba asesorado por profesionales jurídicos, independientemente de si la asesoría fue o no adecuada. La jurisprudencia argentina ha sido clara al determinar que la lesión no busca proteger al imprudente ni al que actúa en forma irreflexiva ${ }^{5}$. Para ilustrar esta situación, nos referiremos a dos pronunciamientos: el primero, en el que la suscriptora de un sistema de ahorro para fines determinados era una contadora pública, en el que se manifestó que la figura de

45 Pontoriero, F. vs. Luzerne Investiment S. A., CNCom., Sala C, I9 de septiembre de 2008, RCyS, 2008-i i86; Paz, V. vs. Paz, L, Sala Civil y Com., ST Santiago del Estero, io de junio de 2005 , LLNOA, 2005-I I 85 , donde se puso de resalto la edad avanzada de la víctima -90 añoscomo la confianza que existía entre esta y los demandados, demostrativas de la situación de inferioridad que habilita la aplicación del art. 954 del Código Civil.

46 Apostolado de la Oración vs. Cantos, J., CCiv. y Com. 2. ${ }^{a}$ Nom., Santiago del Estero, I3 de agosto de 2008, LLNOA, 2008-i I I9.

47 En este mismo sentido, ver en la doctrina italiana a Gentili, A., Trattato del contratto, t. Iv, Milano, Giuffrè, 2006, 454; en Argentina a Mosset Iturraspe, J., Contratos, Buenos Aires, RubinzalCulzoni, 1995 , p. 176.

48 M. N. de J. vs. P. L. G., CNCiv., Sala B, 29 de septiembre de 2006, La Ley, 2007-B, 804.

49 Hotel Presidente vs. Sanelco S. A., CNCom, Sala C, 3 de Julio de r 995, La Ley, I995-E, 277; Salones Acevedo vs. G. C., CNCiv., Sala F, I2 de mayo de I997, La Ley, I997-E, 239, donde se afirmó que en el ámbito de la lesión subjetiva no puede presumirse necesidad, ligereza o inexperiencia de una sociedad anónima que actúa, por esencia, en el tráfico mercantil, representada por sus apoderados, pues estos entes operan jurídica y económicamente con suficiente conocimiento del medio y muchas veces con asesoramiento cuando deben contratar; Emprendimientos Bariloche s/concurso preventivo s/inc. Revisión, Cf. sт Río Negro, Patagonia, i 9 de noviembre de 2007, 200, 8-I 72.

50 Salones Acevedo vs. G. C, CNCiv., Sala F, I 2 de mayo de I997, La Ley, I997-E, 239; Sánchez, D. vs. Rea, R., CNCiv., Sala K, 2 I de diciembre de I998, La Ley, I999-C, 476; DJ, I999-2-859; C. C. A. vs. C. S. M., CNCiv., Sala E, 29 de abril de I998, La Ley, I999-A, 406; DJ, I999-2-39. 
la lesión no pretende la anulación de contratos fruto de errores inexcusables ${ }^{5}$. El segundo caso negó la nulidad de un convenio de división de sociedad conyugal, pues quien la solicitó era un abogado que, además, había sido asesorado por profesionales en la fase previa del negocio ${ }^{5}$.

\section{Elementos subjetivos que atañen al lesionante}

En la figura de la lesión, se tiene en cuenta el comportamiento del lesionante que busca obtener utilidad o favorecerse de la vulnerabilidad del otro contratante que se halla en estado de necesidad, debilidad psíquica o inexperiencia. Esa conducta debe ser voluntaria e intencional 53 y se requiere el dolo, pues como lo ha afirmado la jurisprudencia "[...] se requiere en el explotador lesionante, el uso del artificio o maquinación, aserción de lo que es falso o disimulación de lo verdadero" 54 . El aprovechamiento ha sido identificado como el elemento central de la lesión, sin el cual no se configura esta figura, pues permite caracterizarla y resaltar el comportamiento a ser sancionado ${ }^{55}$, paradigma de la vulneración del principio general de la buena fe ${ }^{5}{ }^{6}$. Se evidencia esta situación en un fallo en el que se declaró la nulidad de un contrato de compraventa en el que la parte demandada adquirió la nuda propiedad de un inmueble de la parte demandante quien conservaba el usufructo vitalicio ${ }^{57}$. En este caso, la actora era una mujer mayor que no quería vender el único bien de su propiedad, pero lo hizo por temor de ser internada en un hogar geriátrico y bajo la creencia inicial de que iba a firmar un testamento; la sugerencia de cambiar su intención original de firmar un testamento bien pudo implicar un aprovechamiento de su situación de desamparo.

En otro fallo que ilustra esta misma problemática se declaró nulo el acuerdo entre el demandado y la madre de la víctima que murió electrocutada al realizar unas labores en la casa de aquel, pues la madre renunció a ser indemnizada por los daños y perjuicios derivados de la muerte de su hijo y aceptó únicamente los gastos fúnebres ${ }^{8}$. Con este convenio firmado el mismo día del trágico evento, el

5 I Murad, A. vs. Lloyds Bank, CNCom., Sala A, I4 de noviembre de 1997, La Ley, I998-B, 699; DJ, I 998-3-I42.

C. J. vs. G. F., CNCiv., Sala I, 23 de mayo de 2002, DJ, 2002-2-I 22 I.

53 SACco, R., op. cit., 364 .

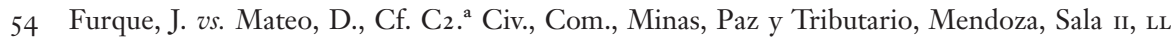
Gran Cuyo, I999-62 I; Establecimiento Frutícola vs. Coto C.I.C.S.A, Cf. CNCom., Sala B, I 9 de julio de 2002, La Ley, 2003-A, I 2.

55 Moisset de Espanés, L., op. cit., 97; Mirabelli, G., op. cit., 587.

56 Llambías, J. J., Código civil anotado, cit., t. II-в, п Iо.

57 Zorrilla, F. vs. Anderle, L., CNCiv., Sala E, 2 diciembre de 2005, La Ley, 2006-B, 360.

$5^{8}$ Guevara, S. vs. Ritacco, R., CCiv. y Com. Mercedes, Sala I, I 2 de octubre de 2006, Llba, 200734I; ED, 22 I-573. 
demandado explotó el estado de necesidad de la madre producto de su falta de recursos e inexperiencia para limitar su responsabilidad.

\section{Prueba de los elementos constitutivos de la lesión}

La jurisprudencia argentina ha indicado que la víctima debe probar los elementos subjetivos que le atañen y que estos eran conocidos del lesionante ${ }^{59}$, además de probar la ventaja patrimonial evidentemente desproporcionada ${ }^{60}$.

Es importante señalar que, si bien la carga probatoria resulta extremadamente rigurosa en cuanto al propósito de aprovechamiento, esta se ve matizada, pues según el artículo 332 del CCCN se presume, salvo prueba en contrario, la existencia de la explotación en caso de notable desproporción de las prestaciones. De esta manera, se invierte la carga de la prueba, ya que le corresponde al lesionante acreditar que la desproporción que se alega se encuentra justificada ${ }^{6 \mathrm{I}}$, o que no medió una situación de inferioridad o que no se presentó la explotación de tal situación ${ }^{62}$.

En caso de duda, la interpretación es restrictiva, haciéndose prevalecer la validez del acto, presumiéndose que las declaraciones de voluntad que este contiene se han realizado de acuerdo con lo que las partes han querido, protegiéndose de esta forma la estabilidad de las convenciones y el respeto debido a lo pactado libremente ${ }^{6}$.

En Colombia, para determinar el elemento objetivo en la lesión, según el caso, como sucede en la compraventa de bienes inmuebles, puede ser necesario el dictamen pericial para determinar el justo precio y así probar si se presenta el desequilibrio establecido por la ley. Ahora bien, la jurisprudencia colombiana ha considerado que le corresponde al juez valorar la prueba pericial "para verificar la firmeza, precisión y calidad de los fundamentos en que se sustenta, de conformi-

59 Furque, J. vs. Mateo, D., C2 ${ }^{\text {a }}$ Civ., Com., Paz y Trib., Mendoza, Sala II, LL Gran Cuyo, I99962 I; Llanos de Ferreira, V. vs. Abdenur, A., $\mathrm{C}_{2}{ }^{\mathrm{a}}$ Civ. y Com. Santiago del Estero, I4 de abril de I998, LLNOA, I 998-I420.

60 Almagro Construcciones vs. Agosto, E., CNCiv., Sala A, 4 de diciembre de I992, La Ley, I994B, 577; Risolea, H. vs. Bosello, E., CCiv. y Com. San Isidro, Sala I, I I de mayo de i995, LLBA, I 996-3 I I; Davidoff, C. vs. Lynch, R., CCiv. y Com., Lomas de Zamora, Sala II, I de abril de I997, Llba, I997-I028; Banco de Galicia y Buenos Aires vs. Vallejo de Paz, M., cs Tucumán, Sala Civil y Penal, i9 de marzo de i 998, La Ley, i 998-F, 8 I 7.

6 I Llambías, J. J., Código civil anotado, cit., t. II-в, I Iо.

62 Gómez, C. vs. Álvarez, G., CNCiv., Sala H, 2 de octubre de r996, La Ley, I998-B, i 2.

63 Salones Acevedo vs. G. C., CNCiv., Sala F, I 2 de mayo de I997, La Ley, I997-E, 293; DJ, I9973-462; Sánchez, D. vs. Rea, R., CNCiv., Sala K, La Ley, I999-C, 476; DJ, I999-2-859; C. C. A. vs. C. S. M., CNCiv., Sala E, I 9 de mayo de I998, La Ley, I999-A, 406; DJ, I999-2-39; Avataneo, H. vs. Coassin, R., CCiv. y Com. Santa Fe, Sala I, 6 de mayo de 200 I, LL Litoral, 2002-233. 
dad con lo dispuesto en el artículo 24I del C. de P. C"64. En este caso, se solicitó la rescisión de un contrato de compraventa de un inmueble rural, pues el precio pactado ascendía a la suma de $\$ 35$.286.6 I 5 de pesos, pero se alegó que a la fecha de celebración del contrato el bien enajenado valía más de \$i26.954.000, lo cual hacía que el precio acordado se tipificara, según la ley, en una lesión enorme ${ }^{65}$. La jurisprudencia advirtió en este proceso que la lesión enorme no es un vicio que afecte al consentimiento, o que tenga causa en un comportamiento u omisión errada de las partes, sino que implica un vicio objetivo que consiste en la desproporción económica establecida por la ley en el caso de la compraventa y que debe corregirse por razones de equidad para restaurar el equilibrio que debe imperar en estas en los contratos sinalagmáticos. En el caso comentado, pese a la existencia de un dictamen pericial que establecía que el precio del contrato era justo, la sala consideró que este avalúo no era idóneo, ya que el valor real del inmueble vendido era desproporcionadamente superior al que recibió el vendedor.

\section{V. Ámbito de aplicación}

En el derecho argentino, como se ha explicado, la lesión tiene una consagración general, pero se requiere de la presencia tanto de un elemento objetivo como de uno subjetivo.

En el derecho colombiano, por el contrario, la lesión está contemplada solamente en algunos casos señalados por la ley teniendo como base exclusivamente el elemento objetivo de la desproporción indicada en cada caso. Estos casos señalados taxativamente por la ley para que opere la lesión son los siguientes:

- Compraventa de bienes inmuebles: los artículos r946 y i 947 del Código Civil colombiano establecen que el contrato de compraventa podrá rescindirse por lesión enorme y que esta se configura "si el precio que recibe el vendedor es inferior a la mitad del justo precio de la cosa que vende; y el comprador a su vez sufre lesión enorme, cuando el justo precio de la cosa que compra es inferior a la mitad del precio que paga por ella”. Más adelante, el artículo i 949 descarta la procedencia de lesión en la compraventa de bienes muebles.

- Permuta de inmuebles: el artículo i 958 del Código Civil colombiano consagra que las normas sobre compraventa se aplican a la permuta.

- Aceptación de herencia: el artículo r 29 I del Código Civil colombiano establece que la aceptación de la herencia podrá rescindirse en caso de lesión grave, en virtud de disposiciones testamentarias de que no se tenía noticia al tiempo

64 Consejo de Estado, Sala de lo Contencioso Administrativo, Sección Tercera, C. P.: Ricardo Hoyos, I 5 de marzo de 200 I.

65 El artículo 1947 del Código Civil colombiano consagra: "El vendedor sufre lesión enorme cuando el precio que recibe es inferior a la mitad del justo precio de la cosa que vende; y el comprador a su vez sufre lesión enorme cuando el justo precio de la cosa que compra es inferior a la mitad del precio que paga por ella. El justo precio se refiere al tiempo del contrato". 
de aceptarla, entendiéndose por este tipo de lesión aquella que disminuya el valor de la asignación en más de la mitad.

- Partición de herencia y partición de bienes: según el artículo I405 del Código Civil colombiano, quien ha sido perjudicado en más de la mitad de su cuota puede solicitar la rescisión de la partición por lesión.

- Cláusula penal: de acuerdo con el artículo r6o r del Código Civil colombiano, podrá pedirse que se rebaje de la cláusula penal todo lo que exceda al duplo de la cantidad del pacto principal. Cuando, por el pacto principal, una de las partes se obligó a pagar una cantidad determinada, como equivalente a lo que por la otra parte debe prestarse, y la pena consiste asimismo en el pago de una cantidad determinada, podrá pedirse que se rebaje de la segunda todo lo que exceda al duplo de la primera, incluyéndose esta en él.

- Mutuo con interés: en materia de mutuo, según el artículo 223 I del Código Civil colombiano, el deudor podrá solicitarle al juez la reducción del interés convencional al interés corriente, si el interés pactado excede de una mitad al que se probare haber sido el interés corriente al tiempo del contrato.

- Hipoteca: el artículo 2455 del Código Civil colombiano consagra que la hipoteca no puede extenderse a más del duplo del valor de la obligación principal, so pena de reducir la hipoteca a dicho valor.

- Anticresis: de conformidad con el artículo 2466 del Código Civil colombiano, si se estipula que los frutos se pueden compensar con los intereses, esos intereses estarán afectados de lesión enorme de conformidad con las reglas del mutuo.

- Mandato: el Código de Comercio colombiano consagra en el artículo I 264 que, si hay una manifiesta desproporción en la remuneración pactada, el mandante puede solicitar su reducción, pero esta no podrá pedirse cuando la remuneración se pacte o se pague voluntariamente después de la ejecución del mandato.

La ley colombiana, además de limitar la lesión enorme a estos casos, excluye su aplicación a las ventas hechas por ministerio de la justicia (artículo i949 del Código Civil) y a los contratos aleatorios.

Es de resaltar que el artículo I950 del Código Civil colombiano determina que no es válida la estipulación sobre la renuncia a interponer la acción rescisoria por lesión enorme y además se tiene por no escrita la cláusula en la que el vendedor exprese intención de donar el exceso. Sin embargo, estas prohibiciones se refieren al momento de la celebración del contrato, pero la jurisprudencia colombiana ha sido reiterativa al aclarar que es válida la renuncia a interponer la rescisión por lesión enorme con posterioridad a la celebración del contrato ${ }^{66}$.

66 Corte Suprema de Justicia de Colombia, Sala Civil, M. P.: William Namén, 5 de diciembre de 20 I r. En el mismo sentido, ver cClXI, I I92; cas. civ. sentencias de i 8 de diciembre de i929, 
Consideramos que este manejo casuístico de la lesión resulta complejo, pues el legislador dijo que solamente en ciertas hipótesis el desequilibrio excesivo merecía una sanción, tomando criterios como la diferenciación entre bienes muebles e inmuebles que en un contexto socioeconómico decimonónico podían justificarse, pero hoy en día ha perdido vigencia y debe reformularse. Destacada doctrina $^{67}$ ha considerado al respecto que una solución frente a la desueta regulación de la lesión enorme en Colombia se encuentra en el artículo 920 del Código de Comercio colombiano, según el cual "[e]l precio irrisorio se tendrá por no pactado”. Sin embargo, a pesar de la utilidad de esta norma, creemos que se refiere a una hipótesis diferente a las que se pretenden sancionar con la lesión, pues el precio irrisorio ataca la esfera de la inexistencia del negocio, ya que, frente a un precio de tal característica, el negocio no existe por falta de elemento esencial. En cambio, por medio de la lesión se sanciona un contrato que aunque existente es excesivamente desequilibrado desde su origen. Nos encontramos frente a una situación similar: el desequilibrio, pero que tendrá sanciones diferentes según el grado. Ante un precio irrisorio, el negocio ni siquiera debe nacer a la vida jurídica, mientras que, frente a otras situaciones, el precio, sin ser irrisorio, genera una desproporción exagerada.

\section{Efectos}

\section{A. Acciones a que da lugar}

En el derecho colombiano los efectos, dependiendo del caso, como se analizó, serán la rescisión del negocio o la reducción del exceso como aparece en la siguiente tabla:

\begin{tabular}{ll}
\hline \multicolumn{1}{c}{ Rescisión } & \multicolumn{1}{c}{ Reajuste } \\
\hline Compraventa bienes inmuebles & Cláusula penal \\
Permuta de bienes inmuebles & Intereses en el mutuo \\
Aceptación de la asignación sucesoria & Hipoteca \\
Partición de bienes & Mandato \\
\hline
\end{tabular}

En Colombia, la jurisprudencia ha sido enfática al afirmar que la lesión no es un vicio del consentimiento y que la sanción por la lesión es la rescisión y no es

xxxvII, 390; I 7 de agosto de I933, XLI, 50I; Io de diciembre de I934; XLV, bis 73, y 22 de marzo de I952, XLI, 450; 5 de febrero de I958, t. Lxxxvi, 336; 26 de abril de I96I, xCV, 77I.

67 Mendoza, A., Conferencia Congreso Internacional de abogados comercialistas, Ley garantías mobiliarias, Bogotá, Colombia, noviembre 22 de 2016. 
causal de nulidad ${ }^{68}$. En efecto, las nulidades son de carácter taxativo y la lesión en la ley colombiana no está dispuesta como una causal de nulidad ni como un vicio del consentimiento.

En Colombia, según el artículo i948 del Código Civil, el comprador puede evitar la rescisión del contrato de compraventa por lesión enorme si completa el justo precio con deducción de una décima parte y a su vez el vendedor puede restituir el exceso del precio recibido aumentado en una décima parte. Así mismo, de conformidad con este mismo artículo, el demandado por lesión enorme debe solamente los frutos desde la fecha de la demanda, mientras que en los casos de nulidad contra el poseedor de mala fe este debe devolver todos los frutos percibidos o que hubieran podido percibirse desde la posesión de la cosa.

En Argentina, en cambio, la lesión sí es una causal de nulidad. En efecto, el artículo 332 CCCN indica que "podrá demandarse la nulidad o la modificación de los actos jurídicos”, por lo que puede acudirse a una u otra acción, sin perjuicio de la solicitud de daños y perjuicios ${ }^{69}$.

De solicitarse la nulidad, esta se considera parcial en la medida en que una vez restablecido el equilibrio se conserva el negocio jurídico y es relativa según la ley argentina (artículo $388 \mathrm{cCCN}$ ), pues no se ve comprometido el orden público, sino únicamente el interés de los contratantes.

Puede solicitarse otra pretensión dirigida a reajustar el equilibrio del negocio, lo que implicaría una revisión del contrato ${ }^{70}$. La situación anteriormente descrita se presentó en un fallo en el que se decidió reajustar el acuerdo en el cual el demandante había aceptado una indemnización por los daños causados en un accidente de tránsito y renunciado a las acciones legales correspondientes, pues se evidenció una notable desproporción entre los daños causados y lo pagado (se entregó solamente el 38 \% de la indemnización justa), además del aprovechamiento de la situación de inferioridad de la víctima del accidente en cuestión ${ }^{7 \mathrm{I}}$.

La revisión del contrato puede presentarse igualmente si al contestar la demanda de nulidad el aprovechador ofrece el reajuste de las prestaciones. Sin embargo, no podría el demandado reconvenir por nulidad si el demandante solicitó el reajuste, pues la ley no lo legitima para ello ${ }^{72}$.

68 Corte Suprema de Justicia, Sala Civil, M. P.: Ricardo Uribe Holguín, Colombia, I4 de octubre de 1976.

69 Brebbia, R., Código civil y normas complementarias, t. 2B, Buenos Aires, Hammurabi, I998, 6 I 5.

70 Alterini, A. A., op. cit., 383 , cuando afirma que el aprovechador al contestar la demanda puede ofrecer un reajuste de las prestaciones, con lo cual se restablecerá el equilibrio avasallado por el acto lesivo.

7 I Balbuena, E. vs. La Perseverancia Seguros, CCiv., Com. y Garantías en lo Penal, Llba, 2006I09I, Necochea, Argentina, 9 de marzo de 2006.

72 Llambías, J. J., Código civil anotado, cit., t. II-в, I I I . 


\section{B. Legitimación por activa}

En Argentina, según el artículo $33^{2}$ del CCCN, la legitimación por activa corresponde solo al lesionado o sus herederos. Los legitimados pasivos son el aprovechador o sus herederos, siempre y cuando las prestaciones de la víctima hayan ingresado a su patrimonio.

En Colombia, acerca de la legitimación por activa para la acción de rescisión, la jurisprudencia ha considerado que por regla general en los contratos de compraventa de inmuebles puede ser ejercida solamente por quienes concurran a la celebración del contrato de compraventa de inmueble que se hayan visto lesionados con el negocio, de conformidad con el principio de la relatividad de los contratos $^{73}$. También se ha indicado la imposibilidad de adelantar procesos de rescisión por lesión enorme en el contrato de compraventa de bienes inmuebles contra terceros adquirentes de buena fe, ya que no les es oponible el negocio anterior en el que se presentó ese menoscabo ${ }^{74}$. Sin embargo, recientemente se complementó esta posición 75 considerando que tales pronunciamientos parten de una regla general que se basa en el hecho de que la lesión enorme en el contrato de compraventa perjudica únicamente al vendedor o al comprador del bien y en que no puede rescindirse un negocio contra terceros adquirentes de buena fe a quienes no les es oponible el contrato antecedente. Sin embargo, aclara la Corte que no solamente quienes celebraron el contrato pueden verse afectados por la lesión, ya que en el caso en cuestión la acción rescisoria fue promovida por el socio mayoritario de una sociedad que enajenó el lote de terreno que constituía el único activo de la empresa a favor de un tercero. Consideró la Corte que, a pesar de no haber celebrado la compraventa, el socio estaba legitimado para incoar la acción rescisoria por la lesión enorme.

\section{Prescripción}

En Argentina, la acción prescribe a los dos años según el artículo 2562 inciso a) del cccN contados "desde la fecha en que la obligación a cargo del lesionado debía ser cumplida" (artículo 2563 del cccN, inciso e). Aunque si el contrato impugnado constituye un contrato de consumo, de conformidad a lo previsto por el art. 50 de la Ley 24.240 modificado por la Ley 26.36I y ulteriormente por la Ley 26994, anexo II, punto 3.4, el plazo de prescripción establecido es de tres años.

73 Corte Suprema de Justicia, Sala Civil, M. P.: Pedro Munar Cadena, Colombia, I2 de diciembre de 2003 .

74 Corte Suprema de Justicia, Sala Civil, M. P.: Carlos Ignacio Jaramillo, Colombia, 30 de enero de 2007.

75 Corte Suprema de Justicia, Sala Civil, M. P.: Ariel Salazar, Colombia, 8 de febrero de 2016. 
En Colombia, en virtud del artículo I 954 del Código Civil, la acción rescisoria prescribe en cuatro años contados desde la celebración del contrato.

\section{Conclusiones}

El estudio comparado de la regulación de la lesión en Argentina y Colombia resulta particularmente útil, pues se evidencian dos visiones diferentes frente a la problemática de los negocios desequilibrados desde su perfeccionamiento. La lesión en Colombia no responde a las necesidades del tráfico jurídico actual, por cuanto es una figura desueta que puede tomar de la actual legislación argentina elementos para su reformulación.

En Argentina se ha regulado la lesión enorme, de manera que teniendo en cuenta dos elementos (subjetivo y objetivo) se proteja adecuadamente al contratante débil, aunque siempre respetando el principio de la autonomía privada. La observancia de aspectos tanto objetivos como subjetivos permite una consagración general de la figura sin caer en una sobreprotección e injerencia indebida en los negocios entre particulares. Sin embargo, para no restarle eficacia a la sanción, el elemento subjetivo debe presumirse cuando exista excesiva ("evidente" es el término técnico; que se diferencia de "notable") desproporción en las prestaciones, y a la parte beneficiada con el exceso corresponderá probar que no existe estado de necesidad, debilidad psíquica o inexperiencia por parte del afectado.

\section{Bibliografía}

\section{Doctrina}

Alterini, A. A., Contratos civiles, comerciales, de consumo, Buenos Aires, AbeledoPerrot, I998, 38 I.

Barbero, D., Sistema de derecho privado, t. I, n. ${ }^{\circ} 247,529$.

Bianca, M., Diritto Civile. Il contratto, t. 3, Milano, Giuffrè, I987, 647.

Brebbia, R., Código civil y normas complementarias, t. 2B, Buenos Aires, Hammurabi, I998, 6 5 .

Chantepie, G., La lésion, LgdJ, 8.

Cifuentes, S., Negocio jurídico, Buenos Aires, Astrea, I986. 
Dítz-Picazo, L., Fundamentos del derecho civil patrimonial. Teoría del contrato, n. ${ }^{5}$, Madrid, Civitas, I996, 457.

Flour, A., Les Obligations, t. I: L'acte juridique, Francia, Sirei, I 77.

Gentili, A., Trattato del contratto, t. Iv, Milano, Giuffrè, 2006, 454.

Hinestrosa, F., Tratado de las Obligaciones II, vol. I, Bogotá, Universidad Externado de Colombia, 20 I 5 , I 133 .

Llambías, J. J., Código civil anotado, Buenos Aires, Abeledo-Perrot, Io7.

Mendoza, A., Conferencia Congreso Internacional de abogados comercialistas, Ley garantías mobiliarias, Bogotá, Colombia, noviembre 22 de 20 i6.

Messineo, F., Doctrina General del Contrato, t. II, 9, 292.

Messineo, F., Manual de Derecho Civil y Comercial (trad. Melendo, S. S.), t. II, n. ${ }^{\circ}$ ıо, Buenos Aires, Ejea, I97 I, 44I.

Mirabelli, G., Dei contratti in generale, Torino, Utet, I987, 585 .

Moisset de Espanés, L., La Lesión y el nuevo artículo 954, Córdoba, Zavalía, I976, 82 .

Mosset Iturraspe, J., Contratos, t. II-B, Santa Fe, Rubinzal-Culzoni, I995, I 78.

Mosset Iturraspe, J., Interpretación económica de los contratos, n. ${ }^{\circ}$ 9, 265.

Ordoqui, G., Desequilibrio en los contratos, Montevideo, Universidad Católica, 2007,395 .

Pérez Vives, A., Teoría general de las obligaciones, vol. I, 200.

Pothier, R. J., Traité des obligations I, C. I, 39 I y ss.

SAcco, R., Il contratto, Torino, Utet, I975, 362.

Stiglitz, R. S., Contratos civiles y comerciales, Parte General, t. I, n. ${ }^{\circ} 276$, Buenos Aires, Abeledo-Perrot, I998, 299. 
Тові́as, J. W., Algunas precisiones acerca del elemento objetivo de la lesión objetiva subjetiva, La Ley, I 996, $43^{8 .}$

\section{Jurisprudencia colombiana}

Consejo de Estado, Sala de lo Contencioso Administrativo, Sección Tercera, C. P.: Ricardo Hoyos, I 5 de marzo de 200 I.

Corte Suprema de Justicia, Sala Civil, M. P.: Ariel Salazar, 8 de febrero de 20 i6.

Corte Suprema de Justicia, Sala Civil, M. P.: William Namén, 5 de diciembre de 20 I.

Corte Suprema de Justicia, Sala Civil, M. P.: Carlos Ignacio Jaramillo, 30 de enero de 2007.

Corte Suprema de Justicia, Sala Civil, M. P.: Pedro Munar Cadena, I 2 de diciembre de 2003 .

Corte Suprema de Justicia, Sala Civil, M. P.: Ricardo Uribe Holguín, I4 de octubre de 1976.

\section{Jurisprudencia internacional}

Almagro Construcciones vs. Agosto, E., cnciv., Sala A, 4 de diciembre de I992, La Ley, I994-B, 577 .

Arce, S. vs. Parque Automotor, CCiv., Com. y Minería, San Juan, Sala I, I9 de mayo de 2005, LL Gran Cuyo, 2006-I 20.

Balbuena, E. vs. La Perseverancia Seguros, CCiv., Com. y Garantías en lo Penal, LLbA, 2006-Io9 I, Necochea, Argentina, 9 de marzo de 2006.

Caino, J. vs. Baraban S. A., CCiv. y Com. Mercedes, Sala I, 28 de marzo de 2006, ed, $220-588$.

C. C. A. vs. C. S. M., cnciv., Sala E, 29 de abril de I998; La Ley, I999-A, 406; DJ, I999-2-39. 


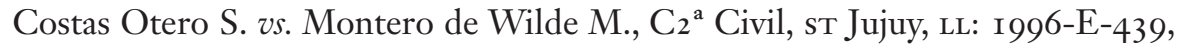
5 de junio de I995.

D’Ambrogio, L. vs. Cottini, C., DJвA, sc Buenos Aires, I48-2352, 7 de marzo de I995.

Davidoff, C. vs. Lynch, R., CCiv. y Com., Lomas de Zamora, Sala II, I de abril de I997, LLBA, I997-IO28.

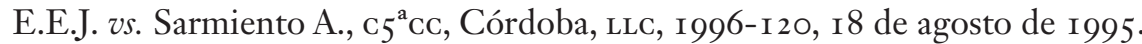

Furque J. vs. Mateo D., Com. Minas, Paz y Tributario, Mendoza, Ll Gran Cuyo, I999-62 I, 2 I de diciembre de I998.

Gómez, C. vs. Álvarez, G., cnciv., Sala H, 22 de octubre de I996, La Ley, I998B, II 2 .

Guevara, S. vs. Ritacco, R., CCiv. y Com. Mercedes, Sala I, I 2 de octubre de 2006, LLBA, 2007-34I; ED, 22 I-573.

Hotel Presidente vs. Sanelco S. A., CNCom, Sala C, 3 de Julio de I995, La Ley, I995-E, 277.

Kuhn, O. vs. Banco de Entre Ríos, Capel, Concordia, Sala III, DJ, I996-2-920, I 5 de febrero de r996.

Llanos de Ferreira vs. Abdenur A., c2 ${ }^{\text {a }}$ CC Santiago del Estero, LL NOA, I 998-I420, I4 de abril de 1998.

Lencina, A. vs. La Principal S. A., CNCom., Sala B, 24 de junio de 2003, La Ley, $2003-\mathrm{F}, 643$.

M. N. de J. vs. P. L. G., CNCiv., Sala B, 29 de septiembre de 2006, La Ley, 2007$\mathrm{B}, 804$.

Murad, A. vs. Llloyd Bank, CNCom., Sala A, I4 de noviembre de i996, La Ley, I998-B, 699; DJ, I998-3-I42.

Macia, L. vs. Banco Hipotecario, CCiv., Com. y Minería, Viedma, 25 de agosto de 2008, LL Patagonia, 2008-603. 
Ortega R. vs. Bco. Bisel S, CCiv. y Com., Rosario, Ll Litoral, 2008-580, 25 de febrero de 2008 .

Pedace, D. vs. Rodríguez, J., CNCiv., Sala A, 27 de octubre de I994, JA, I995IV-69.

Rivarola F. vs. Castillo Sacifia, Documentos y Locaciones, Tucumán, 5 de septiembre de 2004, LLNOA, 2005-5OI.

Salones Acevedo vs. G. C., CNCiv., Sala F, I 2 de mayo de I997, La Ley, I997-E, 239.

Sánchez, D. vs. Rea, R., cnciv., Sala K, 2 I de diciembre de I998, La Ley, I999-C, 476.

Vázquez, E. vs. Huarte Empresa Arg. de Cemento, cnciv., Sala L, 29 de noviembre de i996, La Ley, I997-D, 84.

Von Petery, J. vs. Critto, A., cnciv., Sala L, I9 de febrero de I999, La Ley, 2000C, 9 I I.

Yordano vs. Flores J., CCiv, Com. y Contencioso Administrativo, San Francisco, LLC, I996-ı 098,2 de abril de I996.

Zorrilla, F. vs. Anderle, L., cNciv., Sala E, 2 de diciembre de 2005, La Ley, 2006B, 360 . 